\title{
Posibilidades etnoliterarias en un soneto de Quevedo
}

\author{
M. ${ }^{a}$ ÁNGEles Hermosilla Álvarez \\ Dpto. de Filología Española y sus Didácticas \\ Universidad de Córdoba
}

\section{RESUMEN}

A partir de los postulados de la Estética de la Recepción, que permite unir los actos perceptivos y conceptuales, se plantea la posibilidad de considerar la literatura como una vía de conocimiento del ser humano en una determinada situación, tal como se muestra en el proceso de lectura de un soneto de Quevedo.

Palabras clave: Etnoliteratura, Estética de la Recepción, Quevedo.

\section{SUMMARY}

Following the postulates of Reception Aesthetics, which enables us to connect acts of perception with conceptual ones, the author poses the possibility of viewing literature as a vehicle to get to know human beings in a specific situation, as illustrated by the reading process of one of Quevedo's sonnets.

Key words: Ethnoliterature, Reception Aesthetics, Quevedo.

\section{PRESUPUESTOS TEÓRICOS}

En las ponencias del II Seminario de Etnoliteratura pusimos de manifiesto la capacidad que tiene la creación literaria de "contaminar la realidad, la conducta social, y, por consiguiente, la antropologían, según expresamos en el prólogo del libro que recogía las intervenciones de aquellas jornadas (De la Fuente y Hermosilla, eds. 1997: 7-8), de modo que podríamos empezar a hablar de una disciplina, la etnoliteratura, que tratara de abucear en los comportamientos de los individuos y de los grupos, a través de lo imaginario" (ibid.) Sin embargo, conviene tener presente que, a diferencia del trabajo etnográfico, en la obra literaria los hechos y caracteres son ficcionales y no fotografías de la existencia humana, por lo que se hace necesario, en primer lugar, exponer los postulados que nos

RDTP, LX, 1 (2005): 85-97 
permiten concebir la literatura como un espacio idóneo para indagar en la vida y el sentir de las personas.

Ya desde sus orígenes, en la Poética (1451b: 8-10) de Aristóteles, la teoría literaria cuestionó la dicotomía ficción/realidad al formular el principio de "verosimilitud", un concepto estrechamente relacionado con el receptor, que, inmerso en una determinada cultura que conforma lo real de acuerdo a sus convenciones ideológicas, va refiriendo los personajes y ambientes de los textos literarios a su propia experiencia (Cf. Pozuelo 1993: 18-19). Por ello en la Antigüedad a veces se otorgaba valor de verdad a narraciones fabulosas que hoy no podrían ser creíbles.

En el siglo xx, Karl Popper, influido por la teoría de la relatividad de Einstein, propone como objetivo de la ciencia, en vez de la consecución de la verdad, una serie de propuestas regidas también por el criterio de la "verosimilitud" (Popper 1972: 62-63) y reconoce que las teorías no son una recopilación de observaciones, sino invenciones, conjeturas que han de ser refutadas "si entran en conflicto con observaciones" (Popper 1963: 73). Así, el conocimiento no implica quedarse anclado en el polo hipotético-deductivo o en el inductivo de las observaciones, sino que supone una oscilación entre los dos polos, aunque, según los momentos de la historia, haya existido una preferencia por uno de ellos.

Se trata de un modelo epistemológico que adoptará Gombrich (1959: 24) cuando defiende que no hay ninguna distinción rígida entre percepción e ilusión, una premisa inspirada en la filosofía de la Gestalt (teoría de la forma) alemana ${ }^{1}$, que concibe las formas como conjuntos de relaciones entre elementos percibidos por nosotros como unitarios: los psicólogos gestaltistas enunciaron las leyes de agrupación, entre las que se encuentra la ley de cerramiento, según la cual el observador capta contornos incompletos de una superficie como una figura acabada (Zunzunegui 1989: 39. Cf. asimismo Wertheimer 1945 y Guillaume 1979).

A partir de las proposiciones de Gombrich, Goodman (1968: 38) estudia la relación entre el mundo y el modo de representación artística, una labor de construcción donde la mirada selecciona y organiza elementos de la realidad, pero no de modo fotográfico, sino con la pretensión de que la imagen se nos muestre parecida al objeto y éste igual a la imagen, con lo que se borra la distinción entre lo real y su imagen, y el arte crea la ilusión de vida, pero, lejos de tener anclaje en el referente, su significación es simbólica. De ahí que años más tarde Goodman afirmara:

\footnotetext{
${ }^{1}$ Gombrich, en su libro Arte e ilusión. Estudios sobre la psicología de la representación pictórica, reconoce su deuda intelectual con autores como Ehrenweig, Köhler y Metzger, a los que cita en diversos lugares de su estudio, pero, sobre todo, con Rudolf Arnheim (Gombrich 1959: 22, 76, 351, 338, 342 y 353).
} 
Lo que pienso es que el estudio de las leyes de la forma debe incluir [...] el estudio sobre cómo se relacionan entre sí, dinámica o estáticamente, los procesos y estados que entraña el pensamiento, de cómo influyen y se ven influidos por los símbolos, al ser producidos, percibidos o juzgados, y de cómo las formas de los sistemas simbólicos mediante los que pensamos y que empleamos en nuestras visiones del mundo, determinan las formas de los mundos acerca de los que pensamos y en los que vivimos (Goodman 1984: 54-55).

Estos principios acerca de la obra artística alcanzan su máxima expresión, en lo que a la literatura se refiere, en la corriente fenomenológica, que sigue la línea abierta por Aristóteles, según la cual, como ha subrayado Pozuelo (1993: 106), la ficción literaria es representación mimética en la que el esquema discursivo de las formas de la representación está estrechamente unido a la imagen de vida que conlleva la ficción. En este sentido la teoría fenomenológica, superando las propuestas de la Pragmática, pone de manifiesto que el discurso literario no pertenece al autor - porque no es él quien habla-, sino que proviene de una fuente imaginaria desde la cual se otorga valor de verdad a lo narrado (ibid.: 82-83).

Uno de los estudiosos que, desde esta perspectiva teórica, ha elaborado, en fecha muy temprana, una teoría de la ficción ha sido Martínez Bonati. Basándose en el libro del discípulo polaco de Husserl, Roman Ingarden (1931: 246), que concibe la obra literaria como una estructura esquemática (constituida por cuatro estratos) que ha de ser completada por el lector, considera la ficción como un hablar imaginario:

Al leer un poema adecuadamente, no aprehendemos los signos gráficos como frases [...], sino como pseudofrases, sin contexto ni situación concretos, que representan frases auténticas imaginarias (Martínez Bonati 1960: 128).

De este modo ael autor no se comunica con nosotros por medio del lenguaje, sino que nos comunica lenguaje, (ibid.: 129), que el lector percibe como mundo (poético) donde los actos de habla son auténticos dentro de ese universo ficcional. Es lo que nos ha posibilitado referirnos en nuestro trabajo a "la realidad de la ficción" (Hermosilla 1997: 201) como punto de partida de la etnoliteratura.

Ahora bien, lo que entendemos por realidad en literatura precisa, como ha señalado Darío Villanueva (1991: 498), de la intervención del lector, concebido desde un punto de vista pragmático —el "principio de cooperación" de Grice se revela aquí fundamental - y fenomenológico, que no concibe la obra de arte en plenitud ontológica si no es actualizada por el destinatario: al aceptar el pacto ficcional, la "epojén o suspensión del descreimiento, capta la obra como objeto estético (y no sólo como aobjeto artísticon). Así entra en una convención por la cual proyecta su propia 
experiencia de la realidad sobre la ficción leída, y llega a producir, en términos de Darío Villanueva, "realismo intencional", un concepto que desarrollará más ampliamente, con ejemplos de nuestra literatura, en su libro, Teorias del realismo literario (Villanueva 2004).

En este trabajo dos de los autores que aparecen frecuentemente citados son Jauss e Iser, que, como exponentes de la estética de la recepción alemana, representan las dos líneas complementarias del pensamiento husserliano que guiarán nuestra lectura del soneto de Quevedo a fin de rastrear la condición de la vida humana en el siglo XVII.

Jauss, a partir del concepto de "horizonte", que arranca de Husserl y pasa por Heidegger y Gadamer, analiza la experiencia del lector en la medida en que ésta "entra en el horizonte de expectativas de su vida práctica, preparando su interpretación del mundo e influyendo así en su comportamiento social" (Jauss 1967: 104).

Así pues, la noción de "horizonte de expectativas" ${ }^{2}$ es un conjunto de conocimientos e ideas literarios y extraliterarios (sociales, ideológicos, etc.) que encuentra una obra en el momento de su aparición y que determina la confirmación de las propuestas textuales o su defraudación. Ello depende del grado de "distancia estética", es decir, de "la diferencia entre las expectaciones y la forma concreta de una obra nueva que puede iniciar una 'modificación del horizonte'" (ibid.: 77). En opinión de Jauss, "en cuanto disminuye esta distancia y no se produce ninguna adaptación de la conciencia a experiencias hasta entonces desconocidas, la obra pertenece a la esfera del arte recreativo o 'culinario'" (ibid.: 78). Por el contrario -continúa Jauss (1967: 80)— "hay obras que en el momento de su aparición exceden totalmente el horizonte familiar de la expectación literaria" $\mathrm{y}$, "cuando este nuevo horizonte se ha impuesto, se inicia un cambio del canon estético" que inaugura un movimiento de la historia literaria con la incorporación de aspectos innovadores en las obras y los géneros. Estamos en la línea del pensamiento de Popper de que, como pone de manifiesto Iglesias (1994: 59), la defraudación de las expectativas supone el factor determinante del conocimiento científico: sólo cuando nos vemos obligados a "corregir" nuestros esquemas cognitivos previos se produce el aprendizaje. Este proceso atraviesa por una fase de "fusión de horizontes", a la que se refiere Jauss (1975: 79-80), que, heredada de Gadamer, supone la culminación del diálogo mantenido entre texto y lector en una tarea que no se agota en el estudio de la literatura como

\footnotetext{
${ }^{2}$ El término, introducido por el sociólogo Mannheim y muy utilizado también por Popper, no se ha interpretado siempre con propiedad. Cf. a este respecto Iglesias (1994).
} 
representación artística, sino que pretende indagar en su función dentro de la vida social (Jauss 1967: 113), un enfoque muy útil para nuestro quehacer etnoliterario.

Si Jauss, con el principio de "horizonte de expectativa", realiza una labor en el plano que podríamos denominar macroscópico, Iser, su compañero de escuela, opera en un nivel microscópico, textual. Estudia cómo en el proceso de lectura un texto literario provoca en el lector, gracias a sus "Vacíos", los espacios de indeterminación de Ingarden (Iser 1976: 264276 y 280-309), que le movilizan a la búsqueda del sentido mediante la activación de su imagen de mundo (Iser 1979a: 146), un placer estético, en el sentido etimológico del término (aesthenomai" significa "recibo", "percibo"), un aspecto también subrayado por Jauss (1977: 59-78).

Al mismo tiempo, mediante las "estrategias del texto" (Iser 1976: 143145) que organizan el "repertorio" - los textos precedentes, las normas sociales e históricas, en definitiva, el contexto socio-cultural en su sentido más amplio (Iser 1976: 117) - y sus condiciones de comunicación, se realiza una actividad de construcción que supone una interacción entre el "horizonte de expectativas" formulado por Jauss y las propuestas del texto, gracias a la cual se crea un universo imaginario. Para ello es fundamental el papel que desempeña el "lector implícito" (Iser 1972 y 1976: 55-70), inscrito en la estructura textual, que establece un punto de vista para el receptor -conviene tener presente que, según los autores de la Gestalt, la realidad adquiere significación gracias a la perspectiva- y da lugar a un proceso mediante el que se transfieren las estructuras del texto, a través de los actos de representación, a la experiencia del lector.

$Y$ es que al leer un texto debemos formar siempre imágenes mentales, que, a diferencia de la visión óptica, hacen aparecer aspectos de la realidad que no habían podido imponerse en la percepción directa (Iser 1979b: 154-155). Así, se forman imágenes del mundo, del entorno social, del pensamiento, que en un principio querían escapar a nuestra comprensión (Iser 1989: 212), lo que lleva a Iser (1993: 296) a considerar la representación como una categoría antropológica valiosísima: primero, porque la mímesis literaria no está condicionada por las limitaciones que imponen los organismos institucionales donde se desarrolla la vida humana (ibid.: 297). En segundo lugar, porque lo que no puede hacerse presente y está más allá de la experiencia sólo puede entrar en la consciencia a través de la representación (ibid.: 301) y, como sucede en nuestras actuaciones -sostiene Castilla del Pino-, realizamos escenificaciones, nos reflejamos, si consideramos "reflexionar" como metáfora del "reflejarse una persona ante un espejo" (ibid.: 20), "para que reflexionemos, para que aprendamos de ellas" (ibid.: 22), lo que confirma la función cognitiva de 
la literatura ${ }^{3}$, un aspecto en el que la Estética de la recepción, heredera de la fenomenología de Husserl, coincide con la teoría de la Gestalt.

Ambos movimientos alemanes -uno filosófico, psicológico el otroplantean el problema de la recepción como una actividad del conocimiento: el primero, centrándose en la recepción de los contenidos verbales, conceptuales (es la hermenéutica de la escuela de Constanza); el otro, centrado en la recepción de imágenes visuales. En ambos casos el proceso de recepción no es pasivo. Antes de llevar a cabo un movimiento de observación, vamos al encuentro del objeto con imágenes o ideas "preconcebidas", con esquemas conceptuales u ópticos que son verdaderos "horizontes de expectativas" que proyectamos sobre el mundo exterior $\mathrm{o}$ texto, los cuales confirmarán o refutarán nuestras hipótesis de lectura.

Iser, que funda su teoría en conceptos tales como "indeterminaciones", "estructuras esquemáticas" o "concreciones" ${ }^{4}$, elaborados por Ingarden, consolida sus presupuestos comparándolos con los de Gombrich, que, aunque no pertenece a la teoría de la Gestalt, está, como vimos más arriba, muy influido por ella. Por otra parte, la observación e ilusión en el proceso de lectura detectada por Iser (1976: 158) y otros investigadores como Ritchie (1979b: 158-159) es idéntica al vaivén descrito por Popper, uno de los guías de Gombrich (1959: 23, 24, 231 y 271), característico del conocimiento científico, un proceso que va del polo de las hipótesis al polo empírico de las eventuales refutaciones.

Para destacar los lazos de unión de la escuela de Constanza con la Gestalt, una relación a la que los críticos no han concedido la importancia que merece ${ }^{5}$, hemos elegido un soneto, construido sobre una rica ambigüedad conceptual $^{6}$, de Quevedo, un autor dotado de una especial

\footnotetext{
${ }^{3}$ Una cuestión que, planteada por Aristóteles (Poética, 1451b), subraya Martínez Bonati (1960: 132-133) cuando afirma que "carece de sentido la afirmación de que poesía es comunicación (real). Poesía es un objeto imaginario y, en consecuencia, un acto de conocimiento".

${ }^{4}$ Para "indeterminación" ver Iser (1976: 50-51, 86-87, 97, 101, 261, 267-268, 279280 y 302); para "estructura esquemática" (ibid.: 130, 134-135, 150-154, 152, 165, 188, 226-227, 229-233, 280-282, 287, 289, 290 y 323); para "Concreción" (ibid.: 14, 44, 266269, $270-276$ y 330 ).

${ }^{5}$ César Nicolás (1986), aunque no se basa en los mecanismos de lectura propios de la Gestalt, ha unido afortunadamente los hechos de lectura verbal con un hecho de lectura perceptiva: la estrategia de la anamorfosis, que aplica, también a dos textos de Quevedo.

${ }^{6}$ Como ha manifestado Pozuelo (1999: 31-32), en su Antología poética de Quevedo, el conceptismo se caracteriza por "la trabazón interna de sus poemas y la complejidad de las relaciones entre puntos distantes enlazados por alguna idea que suscita la sorpresa del lector», lo que convierte a este movimiento en un campo muy idóneo
} 
sensibilidad para la pintura, cuya práctica era conocida entre los literatos de su época (Orozco 1988, II: 129-130) y que se manifestaba a menudo en su obra literaria (ibid.: 124-125). He aquí la composición poética:

\section{CALVO QUE NO QUIERE ENCABELLARSE*}

Pelo fue aquí, en donde calavero; calva no sólo limpia, sino hidalga; háseme vuelto la cabeza nalga: antes gregüescos pide que sombrero.

$\mathrm{Si}$, cual calvino soy, fuera Lutero, contra el fuego no hay cosa que me valga; ni vejiga o melón que tanto salga el mes de agosto puesta al resistero.

Quiérenme convertir a cabelleras los que en Madrid se rascan pelo ajeno, repelando las otras calaveras.

Guedeja réquiem siempre la condeno; gasten caparazones sus molleras: mi comezón resbale en calvatrueno ${ }^{7}$.

\section{LECTURA DEL TEXTO}

El soneto comienza con lo que, en un cuadro, sería el título ${ }^{8}$ que, alude, en este caso, a la decisión de un calvo que se niega a ponerse peluca ${ }^{9}$. Si, como ha señalado Orozco (1988, II: 125 y 1989: 43), la co-

para la ilustración de principios teóricos como el de "horizonte de expectativa" de Jauss. Al mismo tiempo la tendencia, en la corriente conceptista, de "construir poemas sobre la base de relaciones que en apariencia son oscuras" la hacen propicia para la aplicación de los postulados de Iser.

- Un primer comentario de este soneto fue leído en mi comunicación "Mecanismos visuales de un soneto de Quevedo", IV Simposio de la Asociación Andaluza de Semiótica (Córdoba, 2-4 de diciembre de 1991).

7 Sigo la transcripción de J. M. Blecua (1970) en su edición de la Obra Poética, II, de F. de Quevedo. Número 527.

${ }^{8}$ El soneto es una composición que subraya el carácter plástico y visual, hasta el punto de que se ha asociado a la noción de "cuadro" (Cf. Scott 1985: 233-234).

${ }^{9}$ La figura del calvo ha sido objeto de frecuente tratamiento en la literatura satírico-burlesca. Quevedo recurre a ella en otros momentos de su obra. Cf. Arellano (1984: 389) y Schwartz y Arellano (1989: 204-205). De este modo constituye un tema ensayado en varias ocasiones hasta conseguir la fórmula adecuada, característica habitual en la poesía de Quevedo. Cf. Senabre (1980 y 1984). 
micidad está determinada no por un hecho, sino por la representación visual, aquí es la imagen implícita en la metáfora que identifica la cabeza con la nalga la que se graba en el lector y desencadena la burla (Orozco 1988, II: 138), aunque el personaje retratado sea puramente aparencial ${ }^{10}$.

Sin embargo, volviendo al título, éste configura un "horizonte de expectativa" en el lector que va a dirigir la lectura de toda la composición: la negativa del sujeto lírico a llevar cabellera postiza.

Efectivamente, la referencia, en el primer verso del primer cuarteto, al cabello encaja perfectamente en ese horizonte: la primera palabra con la que nos encontramos en el proceso de lectura es "pelo", que aparece destacada por el acento rítmico y por la función sintáctica (sujeto) que desempeña. Pero inmediatamente el texto dirige una llamada al receptor mediante el deíctico "aquín, que, al mismo tiempo que aproxima al lector a un detalle concreto, rasgo propio de la pintura barroca (Orozco 1989: 4), nos conduce a un vocablo que llama nuestra atención no sólo por aparecer realzado, al igual que el adverbio, por el acento rítmico, sino por ser una creación léxica, "calavero", que hace referencia al hecho de ponerse calvo, expresado en primera persona (como corresponde a un autorretrato) del presente de indicativo, tiempo verbal que, dominante en todo el soneto, parece plasmar estáticamente la imagen que vamos construyendo.

El segundo verso, que no en vano presenta el mismo tipo de ritmo (sáfico) que el anterior, supone una precisión de éste: "calva no sólo limpia, sino hidalgan, que, mediante la sinécdoque, alude a la condición del personaje retratado: hidalgo y de limpio linaje, es decir, no descendiente ni de árabe ni de judío, como se deduce de la dilogía en la que conviven simultáneamente los significados de pulcritud y limpieza de sangre.

En el tercer verso el lector encuentra una respuesta a la proyección de su horizonte cultural - hay que recordar que la composición del retrato en el canon clásico comienza por la parte superior del cuerpo humano y sigue un orden descendente (Senabre 1997: 13-14) — al reparar en la importancia de la cabeza, sobre la que recae el acento rítmico y que, frente a la posición pospuesta del morfema "me" correspondiente al pronombre personal de primera persona, desempeña la función de sujeto.

Pero la cabeza se compara inmediatamente con "nalga", término que,

${ }^{10}$ El retrato, y sobre todo el autorretrato, en el que el personaje mira a un hipotético lector o espectador con el que parece iniciar una comunicación es una constante, tanto en la literatura como en la pintura del Barroco (Orozco 1988, I: 163 y 1989: LIII). Sobre el retrato literario Cf. Senabre (1997) y, en Quevedo, ver Arellano (1984: 204-206). 
mediante el mecanismo de la paronomasia ${ }^{11}$, subrayado por las isotopías fónicas (recurrencia de líquidas), se relaciona con "calva" e "hidalga". De este modo el lector refuerza fónicamente la nueva imagen que, a tenor de esa identificación que trastoca el orden del retrato clásico, va construyendo. Se trata de una imagen que se le presenta ya distorsionada con respecto al horizonte de expectativas, lo que provoca un lugar de indeterminación o "Vacío", gracias al cual el receptor se siente arrastrado en el placer de la lectura en la medida en que intenta completarlo con su imaginación y la ayuda de otros elementos contextuales. El último verso nos ofrece una consecuencia de lo dicho en el verso anterior: "antes gregüescos pide que sombrero".

El segundo cuarteto se inicia con una condicional "Si [...] fuera Lutero", que sitúa al lector ante una de las amenazas más serias de la época: "contra el fuego - metonímicamente el castigo inquisitorial - no hay nada que me valga". Evidentemente es sólo una hipótesis, pero el temor no desaparece por ello: el personaje retratado no se considera practicante de la religión luterana, pero, por la dilogía que descubrimos en el primer verso, se nos revela como seguidor del hereje de Ginebra: "Calvino soy". Por tanto, sobre el tema central se percibe la posibilidad de una segunda lectura, distorsionadora de la anterior, cuyas líneas, a la manera de lo que sucede en las figuras de la Gestalt, el lector seguirá ahora en un movimiento oscilatorio con respecto a la primera interpretación, a la que, por otro lado, tampoco puede renunciar. La ambigüedad que se pone de manifiesto es el procedimiento en el que se apoya la recepción literaria desde el momento en que su objeto, como indica $\mathrm{M}^{\mathrm{a}}$ del Carmen Bobes (1986: 38), no es lo que "la obra es", sino "lo que puede ser" (ibid.: 18).

Esta nueva lectura refleja los elementos del "repertorio" (del contexto histórico-social y literario) del cual el texto es una concreción. Ahora bien, el cambio de recorrido interpretativo no se basa en la nueva decisión del lector, sino que viene determinado por una serie de signos textuales -hay que recordar la relevancia, en este sentido, del alector implícito", propuesto por Iser, frente al lector empírico- que actúan de llamada de atención hacia un camino diferente: el ritmo acentual, que en el primer cuarteto se mantenía regular (en los cuatro versos se trataba de un endecasilabo sáfico) se rompe en este cuarteto con la aparición de distintos tipos de acentuación. Además, el verbo "valga" actúa de elemento de conexión entre los versos anteriores y el siguiente: "valga" se relaciona paronímicamente con "calva", "hidalga" y "nalga", pero también con "salga", lo que permite la construcción de un intertexto, del que no está ausente la alusión

\footnotetext{
${ }^{11}$ Cf., sobre el procedimiento de la paronomasia en Quevedo, Nicolás (1980: 59-89).
} 
escatológica (CAlva hidalGA), merced al cual es posible rellenar el "vacío" descubierto anteriormente. Desde este enfoque no sólo se anota la condición herética del personaje retratado, sino que se sugiere su pertenencia a un linaje "Sucio", lo que permite interpretar ya el verbo inicial "calavero" como una palabra polisémica que, aparte de designar la acción de "volverse calvo", significa también "volverse calavera", expresando así el inminente peligro que se cierne desde el principio sobre el personaje retratado. En este sentido, "háseme", homófono de "áseme", se nos revela ahora como una voz polisémica extraordinariamente clarificadora. Por consiguiente, la confesión realizada en los primeros versos oculta otra realidad más profunda, paralela a la primera, que se descubre, pues, profundamente irónica.

Pero la ironía continúa, a modo de réplica burlesca de la lectura inocente", en la segunda comparación que se realiza de la cabeza: esta vez con una "vejiga o melón". La disyunción de elementos no es ociosa: "melón", con la referencia al mes de agosto y al "resistero" - que denota el tiempo de mediodía, hasta las dos en el verano, cuando el sol hiere con mayor fuerza ${ }^{12}$, insiste en la amenaza del fuego inquisitorial; "vejiga" alude, al proceder normalmente del cerdo, a la etnia hebrea, a la que podría pertenecer el retratado, al mismo tiempo que introduce la nota de burla: "antiguamente, las llevaban las máscaras y los bufones, rellenas de aire u otra cosa, para golpear con ellas como broma a otras personas" ${ }^{13}$. El primer terceto, dentro de esa dinámica oscilatoria, ofrece dos lecturas posibles: la primera, en consonancia con nuestra primera interpretación, retoma la anécdota del calvo al que pretenden convencer de que lleve peluca; la segunda, condicionada por la proyección del nuevo horizonte descubierto en los versos anteriores, posibilita la construcción de una interpretación bien distinta: ahora se habla de "convertir", lo que, en un contexto donde se alude a la religión, equivale a la obligación de adoptar - como no podría ser de otro modo en una etapa histórica dominada por la Contrarreforma - la verdad católica, concretada en las "cabelleras", que, al constituir una paronomasia con "calaveras", crea un intertexto donde se recoge la amenaza de muerte. La importancia que, desde esta perspectiva, tiene el cabello aparece subrayada por el acento rítmico, que recae en los vocablos que aluden a él.

Sin embargo, la ironía implícita en esa "conversión" se pone de relieve cuando conocemos la verdadera condición de los representantes de la "verdad" católica. La referencia a ellos aparece retardada si, tras la pausa versal, el lector sigue un modelo rítmico de ejecución (Domínguez 1988:

\footnotetext{
${ }^{12}$ Cf. S. de Covarrubias (1987: s.v. "resistero").

${ }^{13}$ Cf. M. Moliner (1983: s.v. "vejiga").
} 
91-92) que provoca una tensión que realza la procedencia de los "conversores": "los que en Madrid rascan pelo ajeno", es decir, los integrantes de la corte, que aparece pintada con los tonos más sombríos.

En efecto, la lectura anecdótica que recoge la creencia según la cual las pelucas se confeccionaban con el cabello de los difuntos va siendo dominada por otra reveladora de una realidad más compleja si recordamos que, como recoge J. L. Alonso ${ }^{14}$ "rascar" tiene el significado de "robar" y, "repelar", en participio pasado pasivo, "golpear" ${ }^{15}$ o, según Covarrubias ${ }^{16}$, "sacar el pelo y particularmente de la cabeza, castigo que se suele dar a los muchachos".

En otros términos, los cortesanos roban a otros utilizando el castigo, que puede llegar a la muerte (tal vez en la hoguera de la Inquisición). De ahí las aliteraciones de velares ("CAbelleras rasCAn CAlaveras", donde se insiste en la alusión escatológica) que unen plásticamente, en el plano fónico, los términos con los que vamos elaborando esta interpretación, contribuyendo, por otro lado, a reforzarla.

Con todos estos elementos el lector puede, finalmente, completar, en el último terceto, la doble imagen que ha venido esbozándose: la mera negativa a llevar peluca por tratarse de una "guedeja réquiem", construcción quevedesca para aludir a pelo de difunto, da paso a una hermenéutica más compleja: si recordarmos que "guedeja" alude al cabello rizado, característico de la raza judía, la proyección de nuestro horizonte cultural reconoce la alusión, mediante la sinécdoque, a los hebreos.

Al mismo tiempo el vocablo "réquiem" posibilita, como sustantivo, la interpretación de la declaración del personaje retratado como una condena a la liturgia católica.

La lectura, basándose en el significado de "calvatrueno", "cabeza del que es vocinglero y hablador, alocado y vacío de $\operatorname{cascos}^{17}{ }^{17}$, se resuelve finalmente en una orientación irónica, distanciadora de la realidad amenazante: "mi comezón resbale en calvatrueno" y en una actitud altanera con respecto a los que quieren "encabellarle" — convertirle" se lee en la otra imagen que entrevemos- a los que imagina con rasgos de animalidad, implícitos en el sustantivo "caparazones", que, junto a "calvatrueno", ofrece una aliteración de velares (CA-CA) que retoman las connotaciones escatológicas ${ }^{18}$. Sin embargo, más que referirse al aspecto físico, la noción

\footnotetext{
${ }^{14}$ Cf. J. L. Alonso (1976: s.v. «rascar").

15 Id.: s.v. "repelado".

${ }^{16}$ Cf. S. de Covarrubias (1987: s.v. "repelarn).

17 Id.: s.v. "calvatrueno".

${ }^{18}$ Cf., acerca de este tema, Goytisolo (1977) y Molho (1970).
} 
de sucio, como señalamos más arriba, apunta al linaje de los que carecen de limpieza de sangre, cuya vida, de acuerdo a la imagen que hemos trazado debajo de las líneas del retrato clásico, se encuentra amenazada por el poder de la Inquisición, una realidad que, en el siglo XVII, aparecía silenciada y sólo podía ser revelada a través de la literatura o el arte.

\section{BIBLIOGRAFÍA CITADA}

Arellano, Ignacio. 1984. Poesía satírico-burlesca de Quevedo. Pamplona: EUNSA.

ARISTÓTEles, Arte poética. 1987, en Aristóteles y Horacio, Artes poéticas: 47-95. Madrid: Taurus.

Blecua, José Manuel. 1970. Francisco de Quevedo. Obra Poética. Madrid: Castalia, 1985. Bobes NAVES, MARía Del CARMEN. 1986. "Lecturas del Cántico Espiritual desde la estética de la recepción", Simposio sobre San Juan de la Cruz. Ávila.

Castilla Del Pino, CaRlos. 2004. Reflexión, reflexionar, reflexivo: 7-62. Discurso de ingreso en la Real Academia Española. Madrid: RAE.

COVARRUBIAS, SEBASTIÁN DE. 1987. Tesoro de la lengua castellana o española. Barcelona: Alta Fulla.

De la fuente lombo, Manuel y Mª Ángeles Hermosilla Álvarez (eds.). 1997. Etnoliteratura: una Antropología de ¿lo imaginario?. Córdoba: Servicio de Publicaciones de la Universidad.

DOMÍNGUEZ CAPARRós, JOSÉ. 1988. Métrica y Poética. Bases para la fundamentación de la métrica en la teoría literaria moderna. Madrid: UNED.

GOMBRICH, ERNST H. 1959. Arte e ilusión. Estudios sobre la psicología de la representación pictórica. Madrid: Debate, 1998.

GOODMAN, NeLSON. 1968. Los lenguajes del arte. Barcelona: Seix Barral.

- 1984. De la mente y otras materias. Madrid: Visor, 1995.

Goytisolo, Juan. 1977. "Quevedo: la obsesión excremental", en Disidencias: 117-149. Barcelona: Seix Barral.

Guillaume, Paul. 1979. La psichologie de la forme. París: Flammarion.

Hermosilla Álvarez, Ma Ángeles. 1996. "Antropología social y Teoría de la literatura: un espacio de confluencia", en M. de la Fuente y M. A. Hermosilla (eds.), Etnoliteratura: una Antropología de ¿lo imaginario?: 187-203. Córdoba: Servicio de Publicaciones de la Universidad.

IgLeSIAS SANTOS, MONTSERRAT. 1994. "La estética de la recepción y el horizonte de expectativas", en D. Villanueva (ed.), Avances en Teoría de la literatura: 35-115. Santiago de Compostela: Universidad.

INGARDEN, ROMAN. 1931. The Literary Work of Art. Evanston: Northwestern University Press, 1973. (Traducción española en Madrid: Taurus, 1998).

ISER, WOLFGANG. 1972. The implied reader. Pattern of Communication in Prose Fiction from Bunyan to Beckett. Baltimore: John Hopkins University Press, 1974.

- 1976. El acto de leer. Madrid: Taurus, 1987.

- 1979a. "La estructura apelativa de los textos", en R. Warning (ed.), Estética de la recepción: 133-148. Madrid: Visor, 1989.

- 1979b. "El proceso de lectura", en R. Warning (ed.), Estética de la recepción: 149164. Madrid: Visor, 1989. 
- 1989. From Reader Response to Literary Anthropology. Baltimore- Londres: The Johns Hopkins University Press.

- 1993. The Fiction and the Imaginary. Charting Literary Anthropology. Baltimore-Londres: The Johns Hopkins University Press.

JAUSS, HANS ROBERT. 1967. "La historia literaria como desafío a la ciencia literaria", en H. U. Gumbrecht et al. (eds.), La actual ciencia literaria alemana: 37-114. Salamanca: Anaya, 1971.

- 1975. "El lector como instancia de una nueva historia de la literatura", en J. A. Mayoral (ed.), Estética de la recepción: 59-85. Madrid: Arco/Libros, 1987.

- 1977. Experiencia estética y bermenéutica literaria. Madrid: Taurus, 1986.

MARTÍNEZ BONATI, FÉlIX. 1960. La estructura de la obra literaria. Barcelona: Ariel, 1983.

MOLHO, MAURICE. 1970. Introducción al pensamiento picaresco. Salamanca: Anaya.

MOLINER, MARÍA. 1983. Diccionario de uso del español, vol. II. Madrid: Gredos.

NICOLÁS, CÉSAR. 1980. "Juegos verbales en la poesía satírica de Quevedo", en Quevedo en su centenario: 59-89. Cáceres: Delegación Provincial del Ministerio de Cultura.

- 1986. Estrategias y lecturas: las anamorfosis de Quevedo. Cáceres: Servicio de Publicaciones de la Universidad de Extremadura.

Orozco, Emilio. 1988. Introducción al Barroco I y II. Granada: Servicio de Publicaciones de la Universidad.

- 1989. Temas del Barroco. De poesia y pintura. Granada: Universidad, edic. facsímil.

POPPER, KARL R. 1963. Conjeturas y refutaciones. El desarrollo del conocimiento científico. Barcelona: Paidós, 1983.

- 1972. Conocimiento objetivo. Un enfoque evolucionista. Madrid: Tecnos, 1988.

Pozuelo Yvancos, José María. 1993. Poética de la ficción. Madrid: Síntesis.

- 1999. Francisco de Quevedo. Antología poética. Madrid: Biblioteca Nueva.

Schwartz, Lía e Ignacio Arellano. 1989. Francisco de Quevedo. Poesía selecta. Barcelona: Promociones y Publicaciones Universitarias.

SCOTT, DAVID. 1985. "Pour une prosodie de l'espace: le sonnet et les arts visuels", en A. M. Christin (ed.), Écritures. II: 227-254. París: Le Sycomore.

SENABRE, RiCARDO. 1980. "Diseños y reelaboraciones en la poesía de Quevedo", en Quevedo en su centenario: 123-135. Cáceres: Delegación Provincial del Ministerio de Cultura.

- 1984. "Sobre el proceso creador en la poesía de Quevedo", Estudios sobre el Siglo de Oro. Homenaje a F. Ynduráin: 463-478. Madrid: Editora Nacional.

- 1997. El retrato literario. Salamanca: Ediciones Colegio de España.

Villanueva, Darío. 1991. "Historia, realidad y ficción en el discurso narrativo". Revista canadiense de estudios bispánicos XV, 3: 489-502.

- 2004.Teorias del realismo literario. Madrid: Biblioteca Nueva.

WeRTHEIMER, MAX. 1945. El pensamiento productivo. Barcelona: Paidós, 1991.

ZunZunegui, SANTOS. 1989. Pensar la imagen. Madrid: Cátedra. 